\title{
Lipid Profile in Flight muscles of Oryctes rhinoceros (Linn, Coleoptera: Scarabaeoidae)
}

\author{
Suvarna More \\ Department of Zoology, P.V.P. Mahavidyalaya, Kavathe Mahankal, Dist. Sangli (M.S.), India 416405
}

\begin{abstract}
The neutral lipids (NL) and phospholipids (PL) with their constituents were studied in the flight muscles of male and female adults of Oryctes rhinoceros, by employing thin layer chromatography (TLC) and bioassay technique. The quantity of neutral lipids in male and female flight muscles were measured 57.501 and $45.894 \mathrm{mg} / \mathrm{gm}$ wet weight of tissues respectively. The main component of neutral lipids was triacylglycerol. The phospholipid values in male and female were 17.26 and $16.85 \mathrm{mg} / \mathrm{gm}$ wet weight of tissues respectively. The NL: PL ratio in male and female adults was recorded to 3:1. The neutral lipids found in six forms. Triacylglycerol was the main component, monoacylglycerol, diacylglycerol, cholesterol, were moderate and cholesterol ester and free fatty acids low in quantity. Phospholipids exhibited seven constituents; phosphatidyl-choline and phosphatidyl-ethanolamine in high concentration, Lysophosphatidyl-choline and sphingomyelin in moderate concentration, and phosphatidyl-inositol, phosphatidyl-serine and phosphatidic acid low in quantity.
\end{abstract}

Keywords: lipids, Male and female, flight muscles, Thin layer chromatography, and Oryctes rhinoceros

\section{Introduction}

Oryctes rhinoceros is the pest of coconut trees. Nirula made a thorough inspection of one million coconut palms heavily infected by the rhinoceros beetle and estimated the annual loss as of $\$ 6,00,000$ to the coconut planters. Recent report of the damage caused by this beetle in Assam and Andaman Islands are very alarming. [20]. According to government of Assam, rhinoceros beetle presents a colossal problem to the coconut industry attacking both young and adult trees. Lipids are bio-chemically important components of insect. Lipid performs a variety of functions in insect physiology. Triacylglycerol is utilized for biological energy [8]. The significance of phospholipids with PC and PE was explained by Locke and Krishnan [16] .Flight is important for insect dispersal. In the jargon of the aeronautics industry, flight pushes the envelope of organism design [6]. The main insect muscles are the leg muscles. Flight muscle is one of the most widely studied light-related tissues in insects mainly because of the variation in the metabolic activity of the different types of muscle [23], [25], [18]. The present report describes the lipid profile in flight muscles of $O$ rhinoceros.

\section{Methods and Materials}

The late third instars larvae and prepupae were collected from dunghill of Agriculture College, near the Shivaji University, campus Kolhapur, (M.S.). They were reared at laboratory and adults were used for flight muscle lipid extraction.

\section{A) Extraction of Lipids}

The flight muscles of male and female adults were weighed and homogenized with $20 \mathrm{ml}$ of chloroform-methanol (2:1 $\mathrm{v} / \mathrm{v}$ ) at room temperature. The homogenates were allowed to stand for 2-3 hours at $4^{0} \mathrm{C}$ and filtered. The filtrate was washed according to Floch et.al; [11] and evaporated in vacuum at $40^{\circ} \mathrm{c}$. The lipid samples were weighed and preserved at $-20^{\circ} \mathrm{c}$ until further use. The total lipid in the sample was determined gravimetrically.

\section{B) Separation of Neutral Lipids and Phospholipids}

The neutral lipids and phospholipids were separated by thin layer chromatography (TLC) using silica gel $G$ and about 200 mesh containing CaSo4, as a binder, (E Merck Germany). The TLC plates $(20 \mathrm{X} 20 \mathrm{~cm}$ ) were prepared according to Wagner et.al [28]. The known quantities of samples dissolved in chloroform were applied with Hamilton's micro syringe (No.8206-B) on activated plates. For neutral lipid the plates were developed in hexane (B.P. $\left.65-70^{\circ} \mathrm{C}\right)$ diethyl ether-acetic acid $(85: 15: 2 \mathrm{v} / \mathrm{v})$ as recommended by Gloster and Flecter [10]. The phospholipid plates were developed in chloroform-methanol-ammonia (115:45:5 v/v) as recommended by Barwal and Kalra [3].The standards of neutral lipids and phospholipids (Sigma,U.S.A.) were co-chromatographed in each respective run and then plates were kept in iodine chamber for identification of individual spots of lipids.

\section{C) Estimation of Neutral Lipids and Phospholipids.}

The iodine was allowed to evaporate and the silica gel from the individual spots of glycerides was scraped and eluted in $1 \mathrm{ml}$ of diethyl-ether and assayed according to Viogue and Holman [27]. The cholesterol and its ester were estimated according to Abell et.al [1]. The rest of the neutral lipid components were assayed titrometrically by the method of Skipski et.al [22]. The phospholipid was determined by the method of Marinetti [17].

\section{Results}

\section{I) Neutral Lipids}

The TLC separation of various neutral lipid components are illustrated in plate No.1, Fig. A; whereas, Table No.1 exhibits quantitative variations in the neutral lipid components.

The neutral lipids in male and female flight muscle were measured 57.501 and $45.894 \mathrm{mg} / \mathrm{gm}$.wet weight of tissues respectively. The neutral lipids consists of six components ; of these triacylglycerol (TG) being the major component. Monoacylglycerol (MG), diacylglycerol (DG) and 


\section{International Journal of Science and Research (IJSR) \\ ISSN (Online): 2319-7064 \\ Index Copernicus Value (2013): 6.14 | Impact Factor (2014): 5.611}

cholesterol (CHO) were found moderate in concentration; whereas free fatty acids (FFA) and cholesterol ester (CE) were occurred low in quantities. The TG concentration in male and female flight muscles was about 48.40 and 40.05 $\mathrm{mg} / \mathrm{gm}$ wet weight of tissues respectively.

\section{II) Phospholipids}

The phospholipids are illustrated in plate No.1, Fig B and Table 2. The phospholipids in male and female flight muscles were measured 17.367 and $15.58 \mathrm{mg} / \mathrm{gm}$.wet weight of tissues respectively. The TLC separation of phospholipids included following constituents; phosphatidyl-choline (PC), ,phosphatidyl-ethanolamine (PE), Lysophosphatidyl-choline (LPC), sphingomyelin (SPG), phosphatidyl-inositol (PI), phosphatidyl-serine (PS) and phosphatidic acid (PA). Among the phospholipids PC and PE were predominant. In male and female flight muscle they measure about 282.1, $260.3 \mu \mathrm{g}-\mathrm{P} / \mathrm{gm}$ and 275.1, $250.5 \mu \mathrm{g}-\mathrm{P} / \mathrm{gm}$ wet weight of tissues respectively. The LPC and SPG were estimated in moderate concentration, whereas PI, PS and PA less in amount.

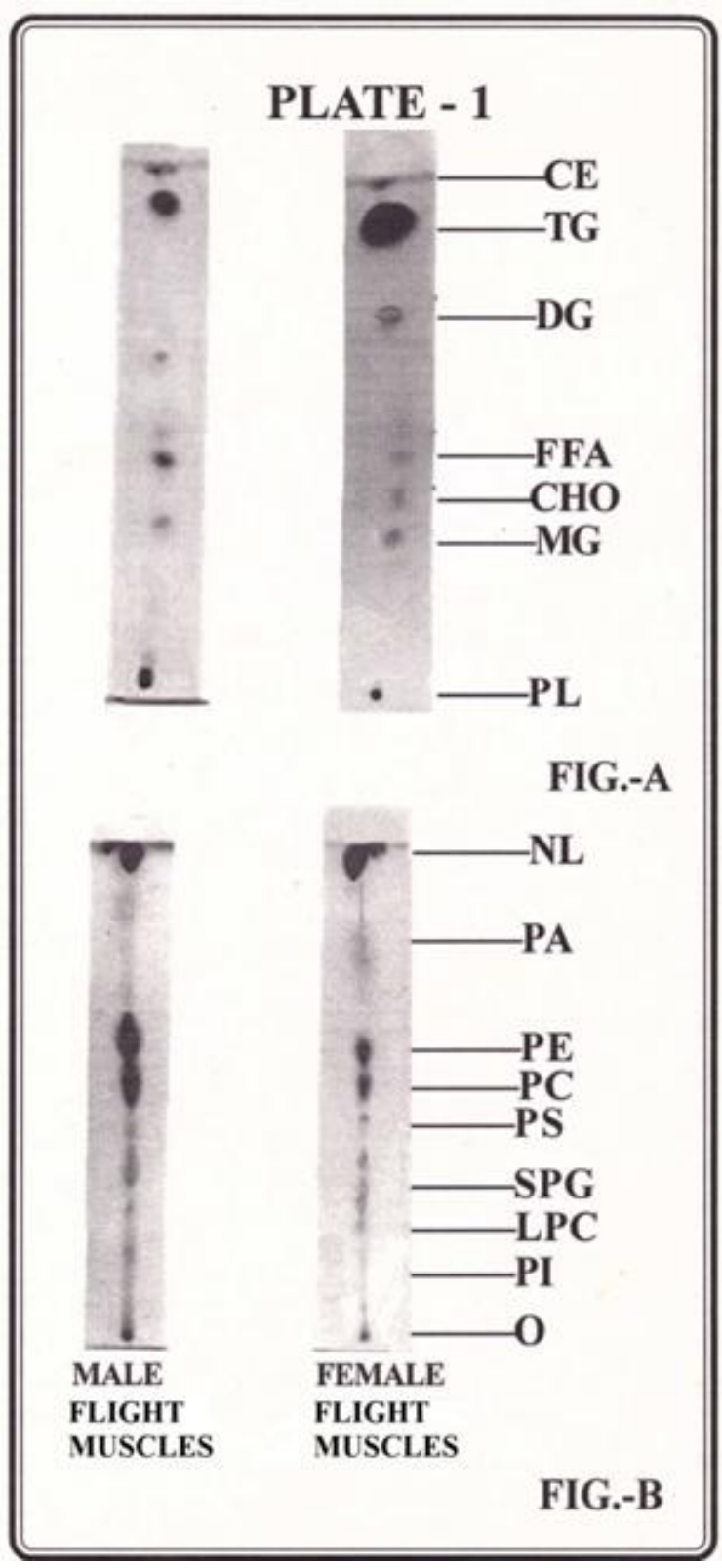

Table 1: Alterations in total lipids, neutral lipids and its components in the male and female Flight muscles of $O$.

rhinoceros

\begin{tabular}{|c|c|c|}
\hline Lipid Type & Male Flight muscles & Female Flight muscles \\
\hline Total Lipids & $74.868 \pm 2.74$ & $61.474 \pm 2.60$ \\
\hline Neutral Lipids & $57.501 \pm 4.15$ & $45.894 \pm 2 . .23$ \\
\hline MG & $1.615 \pm 0.15$ & $1.335 \pm 0.06$ \\
\hline CHO & $1.826 \pm 0.09$ & $0.868 \pm 0.06$ \\
\hline FFA & $0.591 \pm 0.04$ & $1.639 \pm 0.04$ \\
\hline DG & $3.867 \pm 0.16$ & $1.834 \pm 0.06$ \\
\hline TG & $48.40 \pm 3.832$ & $40.05 \pm 1.30$ \\
\hline CE & $1.202 \pm 0.05$ & $0.168 \pm 0.01$ \\
\hline
\end{tabular}

The values for total lipids, neutral lipids and its components are expressed as $\mathrm{mg} / \mathrm{gm}$.wet weight of tissues.

Table 2: Alterations in phospholipids and its constituents in male and female flight muscles of $O$. rhinoceros

\begin{tabular}{|c|c|c|}
\hline Lipid Type & Male Flight Muscles & Female Flight Muscles \\
\hline Phospholipids & $17.367 \pm 0.66$ & $15.58 \pm 0.83$ \\
\hline PI & $15.70 \pm 0.75$ & $10.70 \pm 0.62$ \\
\hline LPC & $56.21 \pm 2.76$ & $35.47 \pm 2.12$ \\
\hline SPG & $51.31 \pm 2.56$ & $30.22 \pm 1.73$ \\
\hline PS & $16.18 \pm 0.75$ & $10.24 \pm 0.51$ \\
\hline PC & $282.1 \pm 4.57$ & $275.1 \pm 13.9$ \\
\hline PE & $260.3 \pm 13.01$ & $250.5 \pm 13.7$ \\
\hline PA & $12.87 \pm 0.64$ & $10.70 \pm 1.03$ \\
\hline
\end{tabular}

The values of phospholipids are expressed as $\mathrm{mg} / \mathrm{gm}$. wet weight of tissues; whereas, values of individual constituents are expressed as $\mu \mathrm{g}-\mathrm{P} / \mathrm{gm}$. wet weight of tissues.

\section{Discussion}

The male flight muscles of Oryctes rhinoceros exhibited high concentration of lipids than the female. The NL: PL ratio in male and female adults was 3:1, indicated that the neutral lipids was dominated over the phospholipid. Among the neutral lipids TG constitute the major component. The TG of the neutral lipids in male and female flight muscles was 48.40 and 40.05 respectively. These findings agreed with the findings on $T$, castaneum [3]. Domroese and Gilbert [9] studied some aspects of lipid catabolism in moth $H$. ceropia. He reported that, the utilization of lipids as a fuel for flight. Lipid is the available substrate as well as the preferred substrate in flight-muscle metabolism in male moths. TG exhibits high concentration in male and female flight muscle and for utilization as energy source [12], [7]. The ratio of CHO: CE in male and female flight muscles $O$. rhinoceros was $1: 1$ and 2:1, respectively.

Phospholipids are expressed as $\mathrm{mg} / \mathrm{gm}$ wet weight of tissues and their values in male and female flight muscles of $O$ rhinoceros were 17.367 and $15.58 \mathrm{mg} / \mathrm{gm}$, respectively. In the present investigation male flight muscles exhibited high phosphplipid contents than female flight muscles. Among the phospholipids the PC and PE were major constituents. The PC: PE ratio was 1:1 which indicated that the PC and $\mathrm{PE}$ are equal in their values. Kallapur et .al [13]. Studied effect of environmental temperature on lipid composition of flight muscle mitochondria in S. gregaria, and observed that elevated temperature resulted in depressed level of PC and increased level of PE. Beenkkers [4] studied transport of 


\section{International Journal of Science and Research (IJSR) ISSN (Online): 2319-7064 \\ Index Copernicus Value (2013): 6.14 | Impact Factor (2014): 5.611}

fatty acids in $L$. igratoria during sustained flight. He reported that, during flight a considerable increase in fatty acid content was indication of an efficient transport of various species of insects by many investigators, such as Van Handel [26] , Locust migratoria migratorioides , Mwangi and Gondsworthy [19], Nilaparrata lugens, Chi [5] and Rhapalosiphium maides Liquido and Irwan, [14], Cheng -Jijiang [6] G. firmus., Zera et.al. [29], Zhang et.al [31] and Zaho and Zera [32]. In insects flight activity usually depends on lipids. [7]. Insect flight muscles do not directly store lipids and require an efficient system to transport hydrophobic fatty acids to the muscle cell which in locusts is mediated by apolipoproteins . Lipid utilization during sustained flight has been studied on lepidopteran and orthopteran species by Norbert [21]. He reported that, in migrating lepidopteran and orthopteran insects, lipid is the preferred fuel for sustained flight activity. Diacylglycerol is delivered by lipophorin to the flight muscle and hydrolyzed to free fatty acid and glycerol. Lipid is the available substrate as well as the preferred substrate in flight-muscle metabolism in male moth [9]. Active fatty acid activating enzymes are present in flight muscle, and fatty acid oxidation in H. cecropia is discussed in relation to vertebrate and other invertebrate systems.[15]. Phospholipid synthesis during flight muscle development in american silkmoth $H$. cecropia was studied by Thomas and Gilbert [24].They found that the major phospholipid fraction of flight muscles and sarcosomes were PC and PE. Atkins studied lipid loss of flight muscle in the beelte Dendroctomus pseudosugae and reported that the flown beetles contained significantly less lipids[2].

\section{Acknowledgements}

Author thanks to Prof. V A. Sawant Dept of Zoology Shivaji University Kolhapur for his encouragement.

\section{References}

[1] Abell, L.L., Levy, B.B., Brodie B.B., and Kendall, F.F. : A simplified method for the estimation of total cholesterol in serum and demonstration of its specificity., J. Biol. Chem. 195, 357-359 (1952).

[2] Atkins M. D. : Lipid loss with flight in the Douglasfir beetle. D. pseudotsugae , Can. Entomol. 101, 164165.1969.

[3] Barwal, R.N. and Kalra, R.L. : Lipids lindane susceptible and resistant strains of $T$. castaneu., Indian J. Expt. Biol., 26, 228-234 (1988).

[4] Beenakkers, A. M. T. : Transport of fatty acids in $L$. migratoria. J. Insect Physiol. 15, 353-361.

[5] Chi. C.R. : Lipid a fuel of flight in brown plant hopper Nilaparrata lugens . ACTA, Biol. Sin. 26. 42-48.

[6] Cheng-Jigiang, Bao-Changzang, Wen-Fengchen, QingWenzhang, Zhang-Wuzhao, Chun-Juan., and Jie-Pingli: Variations in the ultrastructure of the flight muscles of the polymorphic cricket, Gryllus firmus(Orthoptera: Gryllidae Eur. J. Entomol. 109: 579-586, 2012.

[7] Dickinson M. H. and Tum S.: The function of dipteran flight muscle - turning axis and gearbox of the wing base (Insecta, Diptera). Compar. Biochem. Physiol. (A) 116: 223-238.
[8] Downer RGH, Physiological and environmental consideration in insect bioenergetics, In energy metabolism in Insects, Edited By R.G.H. Downer, 1981, 1-17, Plenum Press New York,1997.

[9] Domroese K. A. and Gilbert L. I. : The role of lipid in adult development and flight muscle metabolism in $\mathrm{H}$. cecropia , J. Exp. Biol. 41, 573-590, 1964.

[10] Gloster, J. Flectar, R.F., Quantitative analysis of serum lipids with thin layer chromatography., clin. Chim. Acta., 13, 235-240 (1966).

[11] Folch, J., Lees, M. and Sloane-Stanley A simple method for the isolation and purification of the total lipid from animal tissue. G.H. J.Biol. Chem 226 (1957) 497-509.

[12] Hoffman, A.G.D. and Downer, R.G.H., : End product specificity of TG lipases from intestine fat body muscle and hemolymphy of the American cockroach, $P$. Americana., Lipids., 14, 893-899 (1979).

[13] Kallapur V. L. , Downer R. G. H. , George J. C. and Thompson J. E. : Effect of environmental temperature on the lipid composition of flight muscle mitochondria of S. gregaria , Insect Biochem. 12, 115-122. 1982.

[14] Liquido N. J. and Irwin M. E. : Lipid content and utilization during sustained flight of corn leaf aphid R. maides , Ann. Appl. Biol. 108, 449-460.

[15] Lawrence A. Domroese and Lawrence I. Gilbert: The Role of Lipid in Adult Development and Flight-Muscle Metabolism in Hyalophora Cecropia Journal of Experimental Biology 1964 41: 573-590;

[16] Locke M and Krishnan N, J. Phospholipids and fatty acid composition of $\mathrm{T}$. granarium and biosynthesis of fatty acids during development, Comp. Biochem. Physiol., 39, 1971, 183-194.

[17] Marintti, G.V., : ed. "Lipid Chromatography Analysis". Vol I Marcel Dekker. Inc., New York. (1967).

[18] Menitel T., Duche., Stypah., Mulleru. and Wegenerg. :Central modulatory neurons control fuel selection in flight muscle of migratory locust.J. Neurosci. 23: 11091113., 2003

[19] Mwangi R. W. and Goldsworthy G. J. : Diacylglyceroltransporting lipoproteins and flight in L. migratoria migratorioides . J. Insect Physiol., 27, 47-50.1981

[20] Nirula K. K.: Investigations on the pests of coconut palm. Indian Coconut Journal. 9, 30-37. 1956.

[21] Norbert H. Haunerland : Transport and Utilization of Llipds in Insect Flight muscles, Comp.Biochem, Vol. 11 B7,No. 4 PP.475- 482, 1997.

[22] Skipski, V.P., Barclay, M., Reichman, E.S. and Good, J.J., : Biolchem, Biophys. Acta., 137, 80 (1967).

[23] Sasktor B. . : Regulation of intermediary metabolism with special reference to the control mechanisms in insect flight muscle.Adv. Insect Physiol.7: 267-347., 1970

[24] Thomas K. K. and Gilbert L. I.: Phospholipid synthesis during flight muscle development in the American silkmoyh H. cecropia , Comp. Biochem. Physiol. 21, 279-290, 1967.

[25] Usher Wood P.N.R. (ed.) 1975: Insect Muscle.Academic Press, London, 621 pp 1975.

[26] Van.Handel E. and Nayer J. K. : Direct use of carbohydrate during sustained flight in yhe moth, S. frugiperda. Insect Biochem., 2, 203-208. 


\section{International Journal of Science and Research (IJSR) \\ ISSN (Online): 2319-7064}

Index Copernicus Value (2013): 6.14 | Impact Factor (2014): 5.611

[27] Viogue, E, and Holaman, R.T., : Quantitative estimation of esters by thin layer chromatography., J.Am.oil. chemistis. Soc., 39, 68-66 (1962).

[28] Wagner, H., Horhammer, L. and Wolfe, P., : Thin layer chromatography of phospholipids and glycolipids., Biochem., 2, 175-184 (1961)

[29] Zera A. J., Sall J. \& OtoO K. : Biochemical aspects of flight and flightlessness in Gryllus: flight fuels, enzyme

[30] Activit ies and electrophoretic profiles of flight muscles from flight-capable and flightless morphs. Insect Physiol. 45:275-285. 1999.

[31]Zhang B.C., Jiang C.J., Zhang Q.W. and Zhao Z.W. : Varia-tions in fuel use in the flight muscles of wingdimorphic Gryllus firmus and implications for morphspecific dispersal.Enviorn. Entomol.40: 1566-1571., 2011.

[32] Zhao Z.W. \& Zera A.J. : Differential lipid biosynthesis underlies a tradeoff between reproduction and flight capa-bility in a wing-polymorphic cricket. PNAS99: 16829-16834.2002. 